\title{
PENGEMBANGAN PEMBELAJARAN MOTORIK HALUS ANAK TK A MELALUI MEDIA FIGURE GROUND METEAL INSETS DI RA SYIHABUDDIN MALANG
}

\author{
Ari Kusuma Sulyandari ${ }^{a, 1}$, Eka Rosadah ${ }^{2}$, Dwi Wasilah Wati ${ }^{3}$ \\ ${ }^{a}$ Universitas Islam Malang, Indonesia \\ ${ }^{1}$ ari.kusuma@unisma.ac.id; ${ }^{2}$ ikarosadah10@gmail.com,${ }^{3}$ dwiwashilahwati97@gmail.com
}

\begin{abstract}
Informasi artikel
Received :

Februari 08, 2022.

Revised :

Februari 13, 2022

Publish :

Maret 03, 2022

Kata kunci:

Motorik halus,

Anak usia dini,

Media Figurre

Ground Meteal

Insets.
\end{abstract}

\section{Keywords:}

Fine Motor

Early childhood,

Media Figure Ground

Metal Insets.

\begin{abstract}
ABSTRAK
Tujuan penelitian ini adalah membantu perkembangan menulis awal anak dengan media figure ground meteal insets. Penelitian ini dilaksanakan di RA Syihabuddin Malang. Uji coba kecil media tersebut dilaksanakan dengan 6 orang anak kelas A dan uji coba besar dilakukan dengan melibatkan 35 anak kelas A. Metode penelitian ini menggunakan penelitian pengembangan milik Barg and Gall dengan 10 langkah, namun pada penelitian ini hanya digunakan 7 langkah saja. Media figure ground meteal insets adalah media milik Montessori, cara menggunakannya adalah 1) melepas bagian tengah media, 2) menggam-bar sesuai dengan bentuk media, 3) mengarsir gambar. Data yang diper-oleh dari penelitian ini berupa keamanan, menyenangkan dan mudah dilakukan. Hasil dari penelitian ini tentang keamanan media sebanyak 100\%, kemudahan penggunaan media 93,3\% dan tingkat kesenangkan 100\% setelah melalui berbagai uji coba dan evaluasi media. Pengem-bangan pembelajaran ini layak untuk dikembangkan karena prosentase tinggi dan dinyatakan baik dan layak. Kemampuan menulis awal anak-anak juga terstimulus melalui pengembangan media figure ground meteal insets.
\end{abstract}

\section{ABSTRACT}

The purpose of this study is to help the development of children's early writing with the media figure ground metal insets. This research was conducted at RA Syihabuddin Malang. The small trial of the media was carried out with 6 grade A children and the large trial was carried out involving 35 grade A children. This research method used Barg and Gall's development research with 10 steps, but in this study only 7 steps were used. Media figure ground metal insets is a media owned by Montessori, how to use it is 1) removing the center of the media, 2) drawing according to the shape of the media, 3) shading the image. The data obtained from this research are in the form of safety, fun and easy to do. The results of this study about media security as much as $100 \%$, ease of use of media $93.3 \%$ and $100 \%$ pleasure level after going through various trials and media evaluations. This learning development deserves to be developed because the percentage is high and is declared good and feasible. Children's early writing ability is also stimulated through the development of ground metal insets figure media.

This work is licensed under a Creative Commons Attribution-ShareAlike 4.0 International License. Allows readers to read, download, copy, distribute, print, search, or link to the full texts of its articles and allow readers to use them for any other lawful purpose. 


\section{PENDAHULUAN}

Pendidikan anak usia dini sangatlah penting, karena anak-anak memasuki masa golden age sehingga tujuan Pendidikan anak usia dini adalah menyeimbangkan seluruh aspek perkembangan anak (Kartini: 20013). Anak juga memiliki karakteristiknya sendiri yang khas dan unik yang tidak sama dengan orang dewasa serta akan berkembang menjadi manusia dewasa seutuhnya. Sehingga dapat dikatakan bahwa anak adalah anak dan bukan manusia dewasa dalam bentuk kecil. Berikut ini akan dijabarkan tentang hakikat anak. Ditinjau dari segi usia, anak usia dini adalah anak yang berada dalam rentang usia 0-8 tahun (Morrison, 1989). Standar usia ini adalah acuan yang digunakan oleh NAEYC (National Assosiation Education for Young Child). Menurut definisi ini anak usia dini merupakan kelompok yang sedang berada dalam proses pertumbuhan dan perkembangan. Salah satu aspek perkembangan anak adalah fisik motorik halus. Sejak kecil, anak-anak melatik kemampuan motorik halus melalui gerak reflek seperti menggenggam, meraba memegang sesuatu dan merasakan sensasi panas-dingin, kasar-dan halus. (Santrock: 2014). Motorik halus sangat penting karena terhubung dengan kemapuan yakni kognitif, karena anak-anak menunjuk benda dalam menghitung. Koordinasi yang tepat akan mengarahkan anak pada kemampuan hitung yang tepat (Sulyandari, 2016) melatih motorik halus memang memerlukan waktu yang cukup panjang, motorik halus juga sangat penting untuk menulis. Koordinasi jari-jemari diperlukan untuk memegang pensil dengan benar agar anak tak mudah lelah (Ojigho \& Odokuma, 2019).

Hasil observasi prariset didapat hasil yakni: 1) anak-anak bisa bergerak bebas di sekolah, 2) anak-anak cenderung tidak bisa diam saat kegiatan inti, 3) beberapa anak tidak dapat memegang pensil dengan baik, tangan seperti kaku dan sulit digerakkan, 4) pensil yang digunakan adalah pensil kecil. Dari hasil wawancara dengan walimurid didapat hasil sebagai berikut: 1) anak-anak menghabiskan waktu di rumah dengan bermain gadged, 2) alasan orang tua memberi gadged agar anak-anak tidak ramai, tidak mengganggu aktivitas orang tua, 3) jika anak-anak tidak memegang gadged, maka mereka akan bergerak aktif tanpa bisa dikontrol untuk mencari aktivitas lain. Dari hasil prariset tersebut dapat disimpulkan bahwa anak-anak kurang memiliki kesempatan untuk bergerak bebas sehingga tidak bisa tenang di dalam kelas. 
Pengaruh motorik sangat besar terhadap kecerdsan kognitif anak (Afirianto et al., 2021). Kebutuhan anak terpenuhi untuk bergerak bebas, maka anak-anak dapat tenang di dalam kelas dan belajar dengan baik (Faber Taylor \& Kuo, 2009). Pendapat tersebut di atas dapat disimpulkan bahwa kemampuan motorik halus harus dilatih dari motorik kasar terlebih dulu untuk menguatkan otot-otot halus anak. Melalui observasi prariset di RA Syihabbudin tentang kemampuan menulis anak dirasa sangat kurang, mereka belum dapat mewarna dengan baik (tidak keluar garis), anak-anak menekan pensil saat menulis menandakan mereka susah payah mengoordinasikan otot-otot jari. Kemampuan awal anak-anak dalam menggores alat tulis sangat berpengaruh pada kemampuan menulis awal anak.

Media Figure Ground Meteal Insets adalah media yang simpel dan mudah untuk digunakan oleh anak-anak. Anak-anak diminta untuk mengikuti garis dan membentuk berbagai macam bentuk kemudian diarsir. Kemampuan motorik halus dapat dikembangkan dengan metode bermain karena fitrah anak adalah bermain. Dengan metode bermain anak-anak dapat menerima pelajaran yang diberikan termasuk menulis sesuatu, sehingga mempermudah jalan anak-anak mendapatkan pengetahuan dengan metode yang menyenangkan. Metode menyenangkan erat kaitannya dengan fitrah anak, yakni bermain. Terkadang kita abai tentang hakikat bermain anak, sehingga nuansa bermain pad apembelajaran di TK sangat kurang. Bermain memiliki manfaat, salah satunya yakni mengembangkan kecerdasan sosialemosional anak seperti kerjasama, dan membantu menyetimulus perkembangan lain. Dari penelitian terdahulu, bermain di dalam kelas sangat direkomendasikan. (Lynch, 2015).

\section{METODE}

Penelitian ini menggunakan pengembangan milik Barg and Gall (1983:775) yang memiliki 10 langkah yakni. (1) Melakukan penelitian dan pengumpulan informasi (kajian pustaka, pengamatan kelas, persiapan laporan pokok persoalan). (2) Melakukan perencanaan berupa penyusunan rancangan kegiatan pembelajaran menggunakan media Figure Ground Meteal Insets yang selanjutnya dievaluasi oleh para ahli. (3) Mengembangkan bentuk produk awal setelah dievaluasi oleh para ahli pembelajaran anak usia dini. (4) Melakukan uji coba lapangan (uji coba kelompok 
kecil) terhadap 6 anak kelompok A. (5) Melakukan revisi terhadap produk awal berdasarkan hasil uji coba lapangan permulaan (uji coba kelompok kecil) utama (sesuai dengan saran-saran dari hasil uji lapangan permulaan). (6) Melakukan uji coba lapangan utama dengan 35 subyek. (7) Melakukan revisi produk (berdasarkan saransaran dari hasil uji lapangan utama).

Tabel 1. alur penelitian

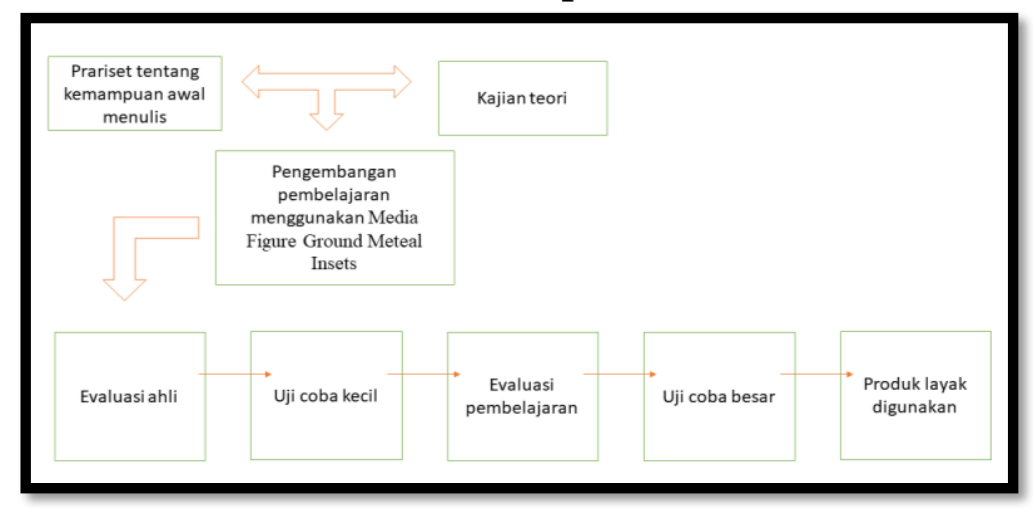

Jenis data yang diperoleh merupakan data kualitatif dan kuantitatif. Teknik analisis data yang digunakan dalam penelitian pengembangan model pembelajaran yang diperoleh dari uji coba kelompok kecil dan kelompok besar terhadap produk adalah data kuantitatif berupa prosentase:

a. Data kualitatif berupa saran dan masukan dari para ahli yang digunakan untuk melakukan revisi terhadap rancangan produk yang dikembangkan.

b. Data kuantitatif berupa prosentase tanggapan para ahli terhadap rancangan produk yang dikembangkan dan kemudahan, kesenangan, serta keamanan anak saat melakukan aktivitas pembelajaran pada anak. Rumus yang digunakan untuk mengolah data berupa data kuantitatif deskriptif prosentase Sudijono (2010:43) sebagai berikut:

$$
P=\frac{f}{N} \times 100 \%
$$

Keterangan:

f : Frekuensi yang sedang dicari presentasinya

$\mathrm{N} \quad$ : Number of case (banyaknya individu), terkait dengan kemudahan, kesenangan, dan keamanan saat melakukan kegiatan.

P : Angka Presentase 
Apabila datanya berupa presentase, proporsi, maupun rasio, maka kesimpulan yang dapat diambil, disesuaikan dengan permasalannya Berikut ini penggolongan presentase kategori yang akan digunakan adalah:

Tabel 2 Deskriptif Presentase

\begin{tabular}{|c|c|c|}
\hline Presentase & Keterangan & Makna \\
\hline $76 \%-100 \%$ & Baik & Digunakan \\
\hline $56 \%-75 \%$ & Cukup & Diperbaiki \\
\hline $40 \%-55 \%$ & Kurang Baik & Tidak digunakan \\
\hline$<40 \%$ & Tidak Baik & Tidak digunakan \\
\hline
\end{tabular}

Data kualitatif diperoleh dari hasil tinjauan para ahli berupa saran dan masukan serta hasil wawancara pada penelitian awal terhadap Figure Ground Meteal Insets. Data kuantitatif diperoleh dari data uji coba kelompok kecil dan kelompok besar melalui angket dan observasi pada saat kegiatan berlangsung, yang diamati adalah kemudahan untuk melakukan, kesenangan anak pada saat melakukan serta aktivitasnya tidak membahayakan bagi anak. Uji coba kecil media tersebut dilaksanakan dengan 6 orang anak kelas A dan uji coba besar dilakukan dengan melibatkan 35 anak kelas A. Data yang diambil dari penelitian ini adalah keamanan, mudah dilakukan oleh anak dan menyenangkan. hal tersebut berdasarkan pada filosofi Montessori (2013) yang lebih mengedepankan kepuasan mental dan fisik anak. Langkah pertama yang harus dilakukan dalam pengembangan pembelajaran ini adalah: 1) guru mengenalkan media tersebut ada anak-anak, 2) setelah guru membagikan media, pensil dan kertas, guru meminta anak-anak untuk melepas bagian tengah media Figure Ground Meteal Insets, 3) setelah bagian tengah terlepas, anakanak meletakkan media tersebut pada kertas, 4) anak-anak menggambar sesuai dengan bentuk media, 5) anak-anak mengarsir gambar yang telah jadi.
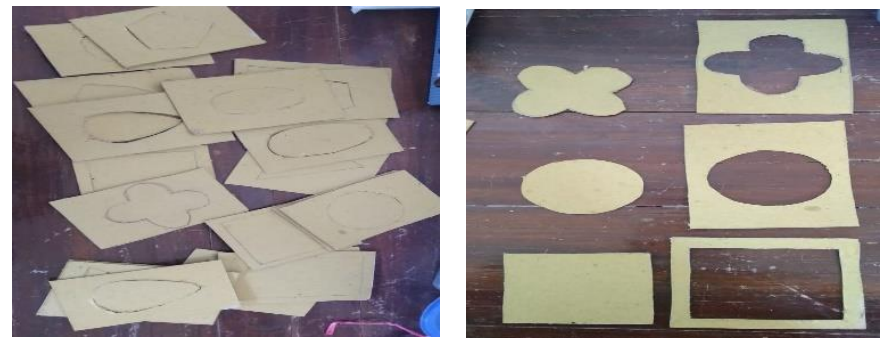

Gambar 1. Media Figure Ground Meteal Insets 


\section{PEMBAHASAN}

Rancangan pembelajaran diuji cobakan terlebih dahulu terhadap kelompok kecil. Data uji coba kelompok kecil menggunakan 6 anak yang menjadi subyek coba. Validasi dilakukan oleh 2 orang validator yaitu ahli media pembelajaran dan ahli pembelajaran anak usia dini. Kategori mudah adalah ketika subyek coba dapat melakukan aktivitas tersebut tanpa kesalahan, jika prosentase kesalahan lebih dari 50\%, maka aktivitas dikatakan sulit, sedangkan dibawah 50\%, maka termasuk kategori mudah. (Wididjoto: 2008)

Tabel 3 hasil uji coba kelompok kecil terkait dengan aspek kemudahan

\begin{tabular}{|c|c|c|c|}
\hline \multirow[t]{2}{*}{ No } & \multirow[t]{2}{*}{ Aspek yang dinilai } & \multicolumn{2}{|c|}{ Data yang diperoleh } \\
\hline & & Mudah & Sulit \\
\hline 1 & Kemudahan anak dalam menggunakan media & $100 \%$ & $0 \%$ \\
\hline 2 & Kemudahan menggambar mengikuti garis pada media & $85 \%$ & $15 \%$ \\
\hline 3 & $\begin{array}{l}\text { Kemudahan anak dalam mengarsir gambar yang } \\
\text { sudah jadi }\end{array}$ & $100 \%$ & $0 \%$ \\
\hline & Rata-rata & $95 \%$ & $5 \%$ \\
\hline
\end{tabular}

Dari data tabel di atas dapat dilihat bahwa rata-rata aktivitas prosentase kemudahan adalah 95\%, maka dapat ditarik kesimpulan bahwa media Figure Ground Meteal Insets bongkar pasang ini mudah dilakukan oleh anak-anak.

Validasi ahli berikutnya adalah tentang aspek menyenangkan. Kedua validator akan menilai apakah Figure Ground Meteal Insets bongkar pasang ini menyenangkan bagi anak atau tidak. Kategori senang dapat dilihat dari wawancara guru dan anak, serta kesediaan anak-anak untuk melakukannya sekali lagi, jika prosentase menunjukkan angka lebih dari 50\%, maka aktivitas dikatakan menyenangkan, sedangkan dibawah 50\%, maka termasuk kategori tidak menyenangkan.

\section{Tabel 4 hasil uji coba kelompok kecil terkait dengan aspek menyenangkan}

\begin{tabular}{|c|l|c|c|}
\hline No & Aspek yang dinilai & \multicolumn{2}{c|}{ Data yang diperoleh } \\
\cline { 3 - 4 } & & Senang & Tidak Senang \\
\hline 1 & Penggunaan media (melepas bagian tengah media) & $100 \%$ & $0 \%$ \\
\hline 2 & Menggambar mengikuti garis pada media & $100 \%$ & $0 \%$ \\
\hline 3 & Mengarsir gambar yang sudah jadi & $100 \%$ & $0 \%$ \\
\hline \hline & Rata-rata & $\mathbf{1 0 0 \%}$ & $\mathbf{0 \%}$ \\
\hline
\end{tabular}

Dari data tabel diatas dapat ditarik kesimpulan bahwa media Figure Ground Meteal Insets ini 100\% menyenangkan pada saat anak-anak menggunakannya, dari 
hasil wawancara guru dan anak dapat diperoleh data bahwa anak-anak senang dan ingin melakukannya sekali lagi bahkan berulang kali, sehingga dapat disimpulkan bahwa media Figure Ground Meteal Insets bongkar pasang menyenangkan bagi anak.

Validasi ahli berikutnya adalah terkait tentang aspek keamanan media. Kedua validator akan menilai apakah Figure Ground Meteal Insets bongkar pasang ini aman digunakan untuk anak. Indikator dari keamanan adalah tidak mencederai anak-anak saat digunakan, jika prosentase menunjukkan angka lebih dari 50\% pada anak yang cedera saat melakukan permainan Figure Ground Meteal Insets, maka dapat dikategorikan tidak aman, jika prosentase dibawah 50\%, maka termasuk kategori aman untuk anak.

Tabel 5 hasil uji coba kelompok kecil terkait dengan aspek keamanan

\begin{tabular}{|c|c|c|c|}
\hline No & \multicolumn{2}{|c|}{ Aspek yang dinilai } & \multicolumn{2}{c|}{ Data yang diperoleh } \\
\cline { 3 - 4 } & & Aman & Tidak \\
\hline 1 & Penggunaan media (melepas bagian tengah media) & $100 \%$ & $0 \%$ \\
\hline 2 & Menggambar mengikuti garis pada media & $100 \%$ & $0 \%$ \\
\hline 3 & Mengarsir gambar yang sudah jadi & $100 \%$ & $0 \%$ \\
\hline & Rata-rata & $\mathbf{1 0 0 \%}$ & $\mathbf{0 \%}$ \\
\hline
\end{tabular}

Dari data tabel di atas, dapat disimpulkan bahwa media Figure Ground Meteal Insets bongkar pasang $100 \%$ aman digunakan untuk anak-anak, karena saat anak-anak melakukan aktivitas menggunakan Figure Ground Meteal Insets tidak terjadi cedera. Dari ketiga tabel tersebut, jika ditarik kesimpulan maka Figure Ground Meteal Insets ini layak untuk digunakan serta tidak perlu adanya revisi pada pembelajaran tersebut.

Data uji coba kelompok besar pengembangan ini melibatkan 36 anak. Aspek yang diamati adalah kemudahan, kesenangan dan keamanan anak dalam melakukan aktivitas tersebut. Pengisian data melalui observasi yang dilakukan oleh dua orang Guru dan peneliti. Hasil dari observasi yang telah dilakukan pada aspek mudah dilakukan oleh anak adalah saat anak-anak mampu melakukan aktivitas Figure Ground Meteal Insets tanpa kesalahan, jika prosentase kesalahan lebih dari 50\%, maka Figure Ground Meteal Insets tersebut dikategorikan sulit, jika prosentase kesalahan kurang dari 50\%, maka dikategorikan mudah. Adapun data uji coba kelompok besar dipaparkan dalam tabel berikut: 
Tabel 6 Hasil uji coba kelompok besar terkait dengan aspek kemudahan

\begin{tabular}{|c|l|c|c|}
\hline No & \multicolumn{1}{|c|}{ Aspek yang dinilai } & \multicolumn{2}{c|}{ Data yang diperoleh } \\
\hline 1 & Kudah & Sulit \\
\hline 2 & $\begin{array}{l}\text { Kemudahan anak dalam menggunakan media } \\
\text { Kemudahan menggambar mengikuti garis pada media }\end{array}$ & $100 \%$ & $0 \%$ \\
\hline 3 & $\begin{array}{l}\text { Kemudahan anak dalam mengarsir gambar yang } \\
\text { sudah jadi }\end{array}$ & $100 \%$ & $20 \%$ \\
\hline & \multicolumn{1}{|c|}{ Rata-rata } & $\mathbf{9 3 , 3 \%}$ & $0 \%$ \\
\hline
\end{tabular}

Data tabel di atas menunjukkan bahwa prosentase kemudahan mencapai 93,3\% dan prosentasi sulit mencapai 6,6\%. Menurut hasil observasi, hal yang sulit dilakukan adalah mengikuti garis bentuk dari media Figure Ground Meteal Insets, namun karena prosentase tinggi, maka layak untuk digunakan karena mudah digunakan oleh anak.

Hasil dari observasi berikutnya adalah terkait aspek menyenangkan bagi anak. Berdasarkan hasil wawancara Guru pada anak dan observasi peneliti. Aspek menyenangkan bagi anak dapat dilihat dari keinginan anak-anak untuk melakukannya lagi serta jawaban pertanyaan anak-anak pada guru menyangkut aspek kesenangan. Jika data yang diperoleh lebih dari 50\%, yang telah dilakukan pada aspek menyenangkan dilakukan oleh anak, namun jika prosentase kurang dari 50\%, maka dapat disimpulkan bahwa tidak menyenangkan bagi anak.

\section{Tabel 7 Hasil uji coba kelompok besar terkait dengan aspek kesenangan}

\begin{tabular}{|c|c|c|c|}
\hline No & Aspek yang dinilai & \multicolumn{2}{c|}{ Data yang diperoleh } \\
\cline { 3 - 4 } & & Senang & Tidak Senang \\
\hline 1 & Penggunaan media (melepas bagian tengah media) & $100 \%$ & $0 \%$ \\
\hline 2 & Menggambar mengikuti garis pada media & $100 \%$ & $0 \%$ \\
\hline 3 & Mengarsir gambar yang sudah jadi & $100 \%$ & $0 \%$ \\
\hline & Rata-rata & $\mathbf{1 0 0 \%}$ & $\mathbf{0 \%}$ \\
\hline
\end{tabular}

Dari data tabel di atas dapat ditarik kesimpulan bahwa media Figure Ground Meteal Insets ini 100\% menyenangkan, saat anak-anak menggunakannya. Dari hasil observasi juga didapat bahwa anak-anak ingin melakukannya lagi. Sehingga dapat disimpulkan bahwa Figure Ground Meteal Insets ini layak untuk digunakan.

Hasil dari observasi berikutnya adalah aspek keamanan. Pada saat anak-anak melakukan aktivitas Figure Ground Meteal Insets, dan beresiko cedera sampai lebih dari 50\%, maka Figure Ground Meteal Insets tersebut dapat dikategorikan tidak aman 
untuk anak, namun jika prosentase menunjukkan angka kurang dari 50\%, maka dapat disimpulkan bahwa Figure Ground Meteal Insets aman untuk anak.

\section{Tabel 8 Hasil uji coba kelompok besar terkait dengan aspek keamanan}

\begin{tabular}{|c|c|c|c|}
\hline No & Aspek yang dinilai & \multicolumn{2}{|c|}{ Data yang diperoleh } \\
\cline { 3 - 4 } & & Aman & Tidak aman \\
\hline 1 & Penggunaan media (melepas bagian tengah media) & $100 \%$ & $0 \%$ \\
\hline 2 & Menggambar mengikuti garis pada media & $100 \%$ & $0 \%$ \\
\hline 3 & Mengarsir gambar yang sudah jadi & $100 \%$ & $0 \%$ \\
\hline & Rata-rata & $\mathbf{1 0 0 \%}$ & $\mathbf{0 \%}$ \\
\hline
\end{tabular}

Dari data tabel di atas dapat ditarik kesimpulan bahwa media Figure Ground Meteal Insets ini 100\% aman digunakan untuk anak-anak, karena tidak ada yang cedera saat pelaksanaannya. Dari hasil uji coba besar ini dapat disimpulkan bahwa Figure Ground Meteal Insets ini layak digunakan karena telah teruji bahwa aman digunakan oleh anak-anak, menyenangkan dan mudah dilakukan.

Produk pengembangan Figure Ground Meteal Insets bongkar pasang ini telah dikaji melalui proses yang semestinya hingga menjadi produk akhir, melalui beberapa revisi untuk mendapatkan produk yang maksimal. Aktivitas pada Figure Ground Meteal Insets ini pun dirasa mudah, menyenangkan dan taman untuk dilakukan anak. Produk telah dinyatakan layak untuk digunakan karena prosentae terendah adalah 93,3\% maka produk ini dinyatakan baik dan boleh untuk digunakan tanpa perbaikan. Perkembangan anak-anak pada saat menggunakan produk ini lebih terstimulus, terlebih jika guru menyiapkan produk ini sesuai dengan tema. Kemampuan anak-anak distimulus melalui cara mereka memegang pensil, kekuatan otot jari saat mengarsir dan kesabaran saat mengerjakan tugas. Hal tersebut memang sangat penting untuk distimulus, namun harus dengan cara yang menyengkan agar anak-anak merasa senang belajar (Afirianto et al., 2021). Aktivitas menulis harus didukung dengan visual, hal tersebut memudahkan anak-anak untuk menulis karena cara berpikir anak-anak masih kongrit. (Zhao et al., 2015). coretan anak sangat berarti, coretan anak adalah awal mula bentuk menulis, sehinga titik, garis dan coretan anak harus dilatih. Mereka harus diberi ruang guna mengembangkan diri serta mengeksplor diri untuk menemukan gaya menulis mereka dan melatih kekuatan otot kecilnya (Beaty: 1996). 


\section{SIMPULAN}

Pengembangan pembelajaran figure ground meteal insets sangat membantu menyetimulus perkembangan anak, prosentase yang dicapai tentang keamaan media mencapai 100\%, kemudahan penggunaan mencapai 93,3\% dan sangat menyenangkan bagi anak yang ditunjukkan dengan prosentase $100 \%$. Pengembangan pembelajaran figure ground meteal insets menyetimulus otot-otot kecil anak dan melatih kekuatan tangan anak sebelum menulis. Anak-anak diminta untuk mengarsir guna melatih kekuatan otot anak. Media figure ground meteal insets hanya digunakan pada pengembangan pembelajaran menulis awal anak, untuk penelitian selanjutnya dapat dikembangkan lagi untuk pembelajarana nak usia dini yang lain.

\section{UCAPAN TERIMA KASIH}

Terima kasih peneliti ucapkan kepada pihak-pihak terkait dalam penelitian ini terutama RA Syihabuddin Malang. serta pengelola jurnal ABATA yang telah menerbitkan artikel ini.

\section{REFERENSI}

Afirianto, T., Wardhono, W. S., Pelealu, B. N., \& Akbar, M. A. 2021. Media Pembelajaran Calistung Hewan Berteknologi Augmented Reality untuk Menarik Minat Belajar Anak. Jurnal Teknologi Informasi dan Ilmu Komputer, 8(2), 381. https://doi.org/10.25126/jtiik.2021824510

Beaty, J.J. 1996. Skills for Preschool Teachers. New Jersey: Prentice-Hall.

Ds, Ahmad. 2000. Permainan Membaca dan Menulis Di Taman Kanak-Kanak. Jakarta: Departemen Pendidikan Nasional.

Faber Taylor, A., \& Kuo, F. E. 2009. Children with attention deficits concentrate better after walk in the park. Journal of Attention Disorders, 12(5), 402-409. https://doi.org/10.1177/1087054708323000

Hasan, Maimunah, 2012. Pendidikan Anak Usia Dini. Jogjakarta: Diva Press

Kartini, Novalia. 2013. Penerapan Model Pembelajaran Numbered of Head Judul Toghether "Kepala Bernomor" untuk Meningkatkan Kemampuan Kognitif Anak Kelompok B di TK ABA 24 Malang. Jurnal Ilmiah PAUD, 1 (1): halaman 26

Lynch, M. 2015. More Play, Please The Perspective of Kindergarten Teachers on Play in the Classroom @ BULLET. American Journal of Play, 7(3), 347-370.

Montesori, Maria. Tanpa Tahun. Metode Montesori. Terjemah Gutex, Gerald

Mulyasa, H.E. 2012. Manajemen PAUD Bandung: PT Remaja Rosdakarya 
Ojigho, E. J., \& Odokuma, I. E. 2019. Pencil Grip Patterns of Students and Skilled Workers. Journal of College of Medical Sciences-Nepal, 15(1), 53-58. https://doi.org/10.3126/jcmsn.v15i1.19286

Santrock, John W. (1997). Life-Span Development. Terjemah Widyasinta, Benedictine. 2012. Jakarta: Erlangga

Sulyandari, Ari Kusuma. 2016. Representasi simbol matematika dalam aktivitas bermain pada anak TK. http://repository.um.ac.id/63035/ (online) diakses tanggal 4 Februari 2022

Sujiono Yuliana Nurani. 2009. Konsep Dasar Anak Usia Dini. Jakarta: Indeks. Jakarta Zhao, P., Li, S., Zhao, J., Gaspar, C. M., \& Weng, X. 2015. Training by visual identification and writing leads to different visual word expertise N170 effects in preliterate Chinese children. Developmental Cognitive Neuroscience, 15, 106-116. https://doi.org/10.1016/j.dcn.2015.09.002

Wididjoto, Heru. 2008. Penelitian Pengembangan. Jakarta: Depdiknas 